\title{
Safety and efficacy of posterior iris claw intraocular lens fixation in aphakic patients
}

\author{
Rosemary Tomy', Rajkumar Maheshwari', Ansa Parveen Kunhu \\ Muhammed ${ }^{2}$, Venkataramana Kalikivayi ${ }^{2}$, Sajeev Cherian Jacob ${ }^{1}$ \\ ${ }^{1}$ Consultant Ophthalmologist, Ahalia Foundation Eye Hospital, Palakkad, Kerala, \\ India; ${ }^{2}$ Ahalia School of Optometry, Palakkad, Kerala, India
}

\begin{abstract}
Purpose: To assess the indications and visual outcome of eyes undergoing posterior iris fixated intraocular lens (IFIOL) implantation for aphakia, to identify reasons for poor visual outcome, and report occurrence of complications.

Methods: In this retrospective case series study, all cases of posterior IFIOL fixation performed over a 30-month period were identified retrospectively. Preoperative and postoperative evaluations comprised objective and subjective refraction, best corrected visual acuity (BCVA), slit lamp biomicroscopy, applanation tonometry, and dilated fundus examination.

Results: Fifty-six eyes of 56 patients were analyzed. Mean age was $60.55 \pm 17.2$ years. The most common indication for IFIOL implantation was surgical aphakia following complicated cataract surgery ( $n=33 ; 58.9 \%)$ followed by trauma ( $n=10 ; 17.9 \%)$, dropped nucleus/IOL during primary surgery $(n=6 ; 10.7 \%)$, and subluxated/dislocated lens-induced glaucomas $(n=5 ; 8.9 \%)$. BCVA better than or equal to their preoperative BCVA was achieved in $96.43 \%$ patients. The surgical aphakia and paediatric/adolescent groups had the best visual results while the dropped nucleus/IOL group and subluxated lens-induced glaucoma groups fared poorly. On the long-term follow-up visit, the most common complication noted was pigment dusting on the corneal endothelium (65.7\%). Conclusion: The long-term results suggest that posterior IFIOL implantation is a safe and effective method for correction of aphakia and can be used for a wide range of indications in eyes without adequate capsule support. It may be considered an easier and faster alternative with minimal manipulation to anterior segment structures in paediatric and post-traumatic aphakic eyes.
\end{abstract}

Keywords: iris claw, intraocular lens (IOL), aphakia

\section{Introduction}

In aphakic eyes without adequate capsular support for intracapsular or posterior chamber sulcus placement of intraocular lens (IOL), alternative methods of IOL fixation are to be considered. This presents a debate between selection of anterior

Correspondence: Dr. Venkataramana Kalikivayi, Head of the Department, Ahalia School of Optometry, Palakkad, Kerala, India.

E-mail:kalikivayi@yahoo.com 
chamber IOL (ACIOL), scleral-fixated IOL (SFIOL), and iris-fixated IOL (IFIOL)., ${ }^{1,2}$

Primary and secondary implantation of angle supported ACIOLs have reported endothelial cell loss, pseudophakic bullous keratopathy (PBK), uveitis-glaucomahyphaema syndrome, and chronic cystoid macular edema (CME). Surgical risks with scleral-sutured SFIOLs include uveal/choroidal bleeding, damage to the blood-aqueous barrier in the ciliary body due to mechanical pressure of the haptics, chronic inflammation, $\mathrm{CME}$, and a longer surgical time with more intraocular manipulation in comparison to $\mathrm{ACIOL}$ implantation. Furthermore, the transscleral sutures can lead to conjunctival erosions, scleromalacia, and endophthalmitis.,4

Retro-fixated iris claw lens circumvents the aforesaid problems. The implantation of the IFIOL behind the iris better preserves the anatomy of the anterior segment with respect to the iridocorneal angle. The suture less technique lends to operating ease and avoids suture related complications. Its disadvantages may be iris chaffing and requirement of sufficient iris tissue..$^{5-7}$

As there are only few works related to iris claw reported earlier, this work is planned to assess the indications and visual outcome of eyes undergoing IFIOL implantation for aphakia, to identify reasons for poor visual outcome, and report occurrence of complications.

\section{Materials and methods}

All cases of posterior IFIOL fixation performed by a single surgeon over a 30-month period were retrospectively identified. Preoperative data collected included demographics and aetiology of aphakia. Preoperative and postoperative evaluations comprised objective and subjective refraction, slit lamp biomicroscopy, applanation tonometry, and dilated fundus examination. The IOL power was calculated by the SRK-T formula using an A constant of 117.2. Fifty-six patients identified from the operating theatre logbook were called to the hospital for a long-term follow-up evaluation on May 2014. In addition to the clinical examination, optical coherence tomography (CIRRUS HD-OCT Model 400 - Spectral Domain; Carl Zeiss) was also done to evaluate retinal morphology and macular thickness. Visual acuity was converted to Log MAR for statistical ease and analysis was done using Microsoft Excel.

The IFIOL used was Model No. PIC 5580/PIC 5590 from Excel Optics (Chennai, India). It is a single piece biconvex PMMA IOL with an overall length of $8.00 / 9.00 \mathrm{~mm}$ and optic diameter of $5.50 \mathrm{~mm}$. The haptics have fine fissures to capture a fold of midperipheral iris stroma through enclavation, where the iris is virtually immobile, less vascularized, and less reactive. ${ }^{10}$ This makes the IFIOL independent of anterior segment size and conducive to pupillary dilatation.

IFIOL implantations were done under peribulbar anaesthesia except for the 
paediatric patients, who were given general anaesthesia. IFIOL implantation was done as a secondary procedure in the surgical aphakia and trauma groups. The subluxated/dislocated lens induced-glaucoma group underwent pars plana lensectomy + trabeculectomy along with IFIOL implantation. The group in which nucleus/IOL was dropped during primary surgery underwent parsplana vitrectomy + phacofragmentation/ IOL explantation along with IFIOL implantation.

The surgical technique performed for all the patients started with separation of the conjunctiva from adhesions to expose the temporal or superior scleral tunnel of the primary surgery, later opened with an iris repositor. In the absence of a scleral tunnel, a $6 \mathrm{~mm}$ scleral tunnel was made at 12 o'clock. Anterior chamber (AC) was formed with viscoelastic and, if vitreous was noted, automated anterior vitrectomy was performed. Two corneal paracenteses were made diagonally opposite to each other at 3 and 9 o'clock in case of a superior tunnel. The IFIOL was inserted through the corneoscleral tunnel along its long axis and, once in the AC, was rotated such that the haptics were in line with the side ports. Holding the optic of the lens with a lens forceps, one haptic was pushed under the iris and lifted up to create a mild indentation on the iris. Simultaneously, a Sinskey hook was passed through the paracentesis on the same side and the midperipheral iris was enclavated between the claw haptics by applying gentle pressure. End point was noting the dimple at the site of enclavation. Similarly, haptic enclavation on the other side was done. Viscoelastic was then washed out and corneal paracenteses were hydrated. No iridectomy was performed. Postoperatively, topical steroids and antibiotics in a tapering schedule over six weeks were prescribed.

\section{Results}

The data of 56 patients were retrieved from the medical records department of our eye hospital and analysed for 56 eyes that underwent IFIOL. The study group consisted of 33 males and 23 females. The mean age was $59.4 \pm 17.99$ years, with a minimum age range of 1 to 83 years.

IFIOL was implanted most commoly in surgical aphakia following complicated cataract surgery $(n=33 ; 58.9 \%)$. The other etiological factors of aphakic patients who underwent IFIOL are given in Table 1.

Table 1. Aetiology of aphakia

\begin{tabular}{|l|l|l|l|}
\hline S.no & Indication for iris claw lens & Number & Percentage \\
\hline 1 & Complicated cataract surgery & 33 & 58.9 \\
\hline 2 & Penetrating eye injury & 10 & 17.9 \\
\hline 3 & ACIOL complications & 2 & 3.6 \\
\hline
\end{tabular}


Tomy, Maheshwari, Muhammed et al.

\begin{tabular}{|l|l|l|l|}
\hline S.no & Indication for iris claw lens & Number & Percentage \\
\hline 4 & Dropped IOL during primary surgery & 2 & 3.6 \\
\hline 5 & Dropped nucleus during primary surgery & 4 & 7.1 \\
\hline 6 & Subluxated lens-induced glaucoma & 5 & 8.9 \\
\hline & Total & & 56 \\
\hline
\end{tabular}

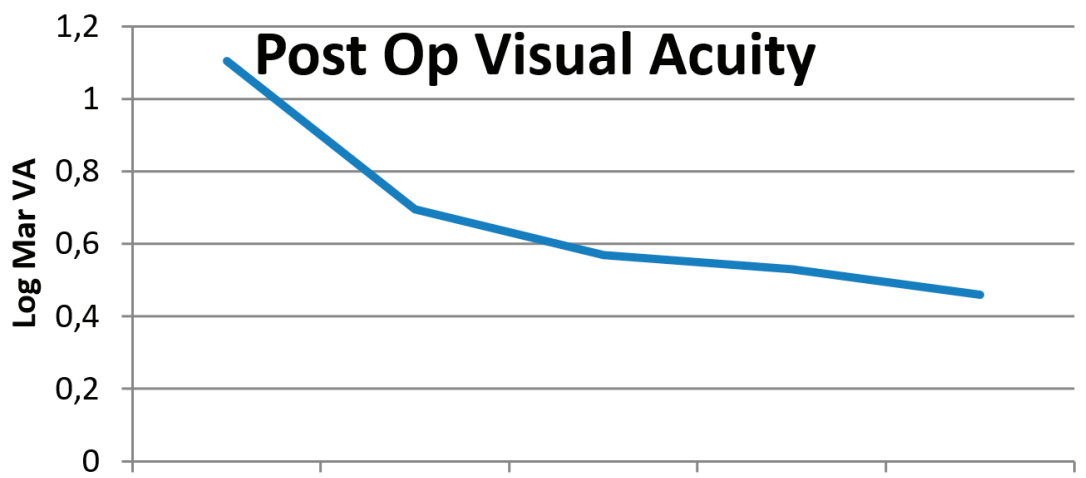

PR OP BCVA PO OP 1 WK PO OP 1MTH PO OP 1YR PO OP 2YR BCVA BCVA BCVA BCVA

Fig 1. Pre- and postoperative Log MAR visual acuity.

The best corrected visual acuity (BCVA) preoperatively was found to be 1.10, which was improved to $0.69,0.57,0.53$, and 0.46 Log MAR for postoperative one week, one month, one year, and two years, respectively, as shown in Figure 1. A paired t-test was performed between the preoperative BCVA and postoperative BCVA, which revealed a statistically significant $p$ value less than 0.05 for all follow-up visits of one week, one month, one year, and two years.

At one-month follow-up, $66.6 \%$ patients achieved BCVA $\geq 6 / 12$ and $83.3 \%$ achieved $B C V A \geq 6 / 18$. Of the $33.3 \%$ patients whose BCVA $<6 / 12$, the causes for decreased vision and co-morbidities are outlined in Table 2. There are two cases where postoperative visual acuity was reduced. The reason for the first case was due to macular puckering following pan retinal photocoagulation for proliferative diabetic retinopathy. The reason for the second case is due to the complications related to retinal detachment. 
Safety and efficacy of posterior iris claw intraocular lens fixation in aphakic patients

Table 2. Ocular comorbidity in BCVA $<6 / 12$

\begin{tabular}{|l|l|}
\hline Comorbidity & No. of Cases \\
\hline Corneal pathology & 2 \\
\hline Retinal pathology & 11 \\
\hline Glaucomatous optic atrophy & 3 \\
\hline
\end{tabular}

\section{Post Op 2 yr BCVA}

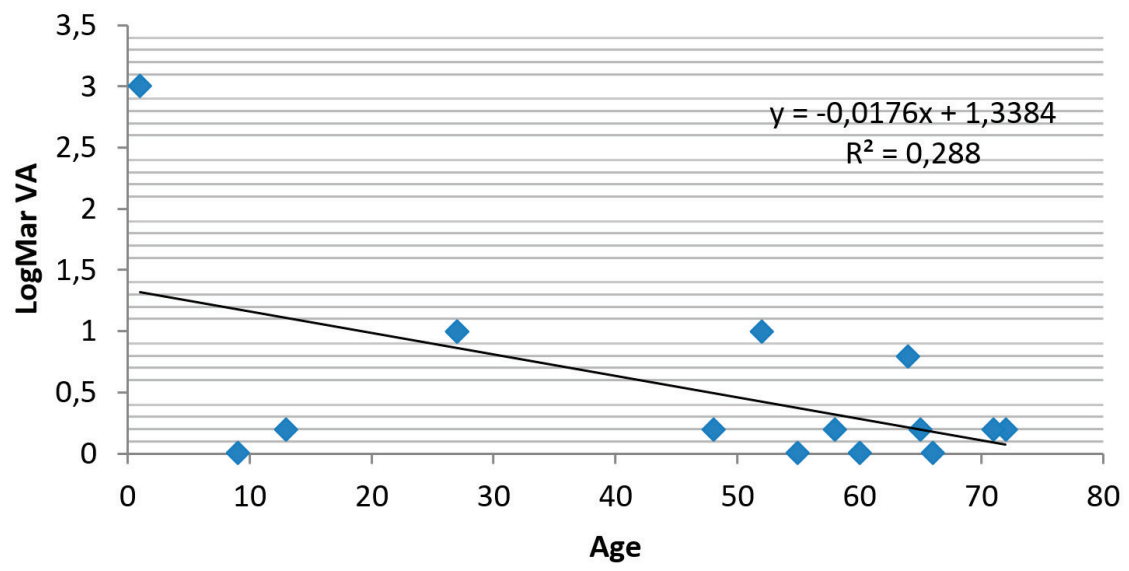

Fig 2. Correlation of age and Log Mar VA for a 2-year postoperative visit.

Pearson's correlation test was used to compare age with best corrected Log MAR visual acuity, which revealed positive correlations with one-week, one-month, and one-year follow-up with no statistical significance. However, it showed a negative correlation for a two-year follow-up with statistical significance of $p<0.05$, shown in Figure 2.

Subjective refraction, intraocular pressure (IOP), and astigmatism data was also recorded for all patients in a follow-up visit to the hospital. The mean preoperative IOP was found to be 15.97 and postoperative IOP was found to be 14.72. A paired t-test was performed and revealed no statistical significance between pre- and postoperative visits in IOP. The mean preoperative and postoperative spherical equivalents were found to be $+8.25 \mathrm{D}$ and $-0.41 \mathrm{D}$, respectively, which revealed a statistically significant difference with $p<0.05$. Keratometry readings for corneal curvatures were also recorded for pre- and postoperative visits. The difference in corneal curvature between both meridians was taken as astigmatism. The mean pre- and postoperative astigmatism was found to be $0.99 \mathrm{D}$ and $1.89 \mathrm{D}$, respectively, and was found to be statistically significant with $p=0.03$. This indicates 
there is a significant increase in postoperative corneal astigmatism after IFIOL surgery.

On slit lamp examination, all the eyes were quiet and all the IFIOLs except one were well centred. The inferiorly decentred IOL was reclipped. Another patient had developed disenclavation four months postoperatively, which had been reclipped and was well centred on long-term follow-up. The most common complication noted was mild pigment dusting on the corneal endothelium in $65.7 \%$ of cases, followed by slight temporal ovalisation of the pupil/irregularities in $40 \%$, more so in the penetrating corneoscleral injury trauma cases. Focal iris atrophy at the enclavation points/diffuse iris atrophy were noted in $40 \%$. The entire postoperative complication rates are given in Table 3.

Table 3. List of complications on long-term follow-up for $>1$ year

\begin{tabular}{|l|l|l|l|}
\hline S.No & Complications & Number & Percentage \\
\hline 1 & Pigments on endothelium & 23 & 65.71 \\
\hline 2 & Pupil ovalisation/irregularities & 14 & 40 \\
\hline 3 & Focal/diffuse iris atrophy & 14 & 40 \\
\hline 4 & IOL decentration & 2 & 5.7 \\
\hline
\end{tabular}

On OCT, the mean Central Macular Thickness was $287.37 \mu$. Three patients had $\mathrm{CME}$, one each in the IOL explantation, trauma, and surgical aphakia groups. Five patients had epiretinal membrane, of which two were post pars plana vitrectomy/ IOL explantation/silicone oil implant/endolaser for IOL/nucleus drop with RD, one was post panretinal photocoagulation for proliferative diabetic retinopathy, one post focal laser for clinically significant macular edema, and one was idiopathic. The visual outcome was analysed with respect to the aetiology of aphakia subgroups, as given in Table 4. The surgical aphakia and paediatric groups had the best visual results. One patient (1.8\%) required a re-operation for IOL decentration, in which IFIOL was reclipped after three months of initial treatment.

Table 4. Subgroup analysis of visual outcome

\begin{tabular}{|l|l|l|l|l|l|}
\hline Subgroups & Trauma & $\begin{array}{l}\text { Surgical } \\
\text { aphakia }\end{array}$ & $\begin{array}{l}\text { Dropped } \\
\text { nucleus/ } \\
\text { IOL }\end{array}$ & $\begin{array}{l}\text { Subluxated/ } \\
\text { dislocated } \\
\text { lens-induced } \\
\text { glaucoma }\end{array}$ & $\begin{array}{l}\text { Paediatric/ } \\
\text { Adolescents }\end{array}$ \\
\hline No. & 10 & 33 & 8 & 5 & 5 \\
\hline $\begin{array}{l}\text { Mean age } \\
\text { (years) }\end{array}$ & 37 & 65.91 & 66.25 & 65.80 & 11.8 \\
\hline $\begin{array}{l}\text { Preop } \\
\text { BCVA }\end{array}$ & $\begin{array}{l}1.450 \pm \\
0.97\end{array}$ & $\begin{array}{l}0.752 \pm \\
0.3726\end{array}$ & $\begin{array}{l}1.113 \pm \\
0.8576\end{array}$ & $2.04 \pm 1.144$ & $1.7 \pm 1.237$ \\
\hline
\end{tabular}


Safety and efficacy of posterior iris claw intraocular lens fixation in aphakic patients

\begin{tabular}{|l|l|l|l|l|l|}
\hline Subgroups & Trauma & $\begin{array}{l}\text { Surgical } \\
\text { aphakia }\end{array}$ & $\begin{array}{l}\text { Dropped } \\
\text { nucleus/ } \\
\text { IOL }\end{array}$ & $\begin{array}{l}\text { Subluxated/ } \\
\text { dislocated } \\
\text { lens-induced } \\
\text { glaucoma }\end{array}$ & $\begin{array}{l}\text { Paediatric/ } \\
\text { Adolescents }\end{array}$ \\
\hline $\begin{array}{l}\text { Postop } \\
\text { BCVA 1 } \\
\text { week }\end{array}$ & $\begin{array}{l}0.34 \pm \\
0.255\end{array}$ & $\begin{array}{l}0.409 \pm \\
0.225\end{array}$ & $0.7 \pm 0.568$ & $0.76 \pm 0.7893$ & $0.34 \pm 0.1140$ \\
\hline $\begin{array}{l}\text { Postop } \\
\text { BCVA 1 } \\
\text { month }\end{array}$ & $0.34 \pm$ & $0.29 \pm$ & $0.57 \pm$ & $0.7 \pm 0.8426$ & $0.320 \pm 0.109$ \\
\hline $\begin{array}{l}\text { Long-term } \\
\text { follow-up } \\
\text { BCVA }>1 \\
\text { year }\end{array}$ & $0.36 \pm$ & 0.207 & 0.304 & $0.241 \pm$ & $0.65 \pm$ \\
0.203 & 0.3559 & $0.325 \pm 0.457$ & $0.28 \pm 0.13$ \\
\hline
\end{tabular}

\section{Discussion}

The aim of posterior IFIOL lens implantation is to achieve acceptable refractive and visual outcomes in patients with insufficient capsular support for intracapsular or sulcus placement of IOL while avoiding the need for aphakic spectacles or contact lenses. ${ }^{5}$ The posterior IFIOL fixation behind the iris plane at the nodal point of the eye combines the advantages of a posterior chamber lens and a short operation time as well as an easy operation technique. ${ }^{6}$

In the present study, $96.43 \%$ patients achieved a BCVA better than or equal to their preoperative BCVA and $66.6 \%$ of patients achieved a final BCVA of $\geq 6 / 12$. This is comparable to the $60 \%$ reported by De Silva et al. ${ }^{8}$ and $63.5 \%$ by Gonnermann et al. ${ }^{9}$ In adult study groups with no ocular comorbidity, Bhandari et al. ${ }^{10}$ and Rao et al. ${ }^{11}$ have reported $70 \%$ and $80 \%$ patients achieving a BCVA $\geq 6 / 12$, respectively, with the same model of IFIOL. In the current study, on evaluating the surgical aphakia group, with no ocular comorbidity, $95.4 \%$ patients achieved $B C V A \geq 6 / 12$. The spherical equivalent values were reduced postoperatively from $+8.25 \mathrm{D}$ and $-0.41 \mathrm{D}$, indicating IFIOL was well placed and good surgical technique for aphakic patients.

On subgroup analysis, the best visual outcome was attained in the post-cataract surgical aphakia group, understandably due to less ocular comorbidity, followed by the paediatric/adolescent group. In the latter group, all five of the children had had secondary IFIOL implantation post-trauma, four of which were following penetrating corneoscleral injuries. On long-term mean follow-up, they attained a statistically significantly better BCVA of $0.28 \pm 0.13$. In the immediate postoperative period, secondary glaucoma and endophthalmitis were identified 
in one child each and successfully managed. They were all undergoing occlusion therapy to avoid amblyopia. Paediatric eyes stand to benefit from minimal manipulation of the sclera and trabecular meshwork, nil sutures, and shorter general anaesthesia span, especially in those children needing multiple surgeries with good long-term results.

In the trauma group, with five post-penetrating corneoscleral injuries and five post traumatic dislocation /subluxation of lens, a statistically significant better BCVA of $0.36 \pm .313$ was seen at long-term follow-up of $>1$ year. Posterior IFIOL is thus a viable option in traumatic aphakia, ${ }^{13}$ especially in penetrating corneoscleral injuries with scarred sclerae and corneas where SFIOL and ACIOL are not wise options.

Patients with subluxated/dislocated lens-induced glaucoma who underwent trabeculectomy + IFIOL implantation as a primary procedure and the nucleus/ $\mathrm{IOL}$ drop group fared poorer in terms of visual outcome on account of their ocular comorbidities. In the former group, owing to late presentation, two of the five patients went into glaucomatous optic atrophy, while the other three had a mean BCVA of 0.2 with well controlled IOP at one-month and long-term follow-up. In the latter group, two patients with RD and one with postoperative CME improved to 0.7 and 0.2 Log MAR, respectively, on long term follow-up.

The most common complication noted here was minimal pigment deposition on the corneal endothelium in $65.7 \%$ of the patients. Pupil irregularities and anterior synaechiae were noted in the penetrating injury patients. Mild temporal ovalisation was seen in $14.2 \%$, similar to the Bhandari et al. report of $10 \%{ }^{10}$ and Gonnermann et al. of $13.9 \% .{ }^{9}$ Pupil ovalisation can be attributed to fixation of the haptic very tightly or asymmetrically. IFIOL decentration was noted in two patients (5.7\%), in agreement with other studies. ${ }^{8,10}$ Inadequate tissue grasping during clipping may have caused the iris-claw haptics to become detached in the long term. However, a complete IFIOL dislocation into the vitreous cavity, when both haptics are detached from their attachment point coincidentally or concomitantly, has not yet been reported in the literature.

On OCT evaluation, ERM was found in $14.3 \%(n=5)$ mostly attributable to past retinal surgery and laser. CME found in $8.57 \%(n=3)$ similar to other studies, ${ }^{9}$ responded well to posterior subtenon triamcinolone injections. Mean macular thickness in other patients was within normal limits.

A limitation of the current study is that endothelial specular counts were not performed preoperatively. However, earlier studies ${ }^{14,15}$ have shown that owing to its distance away from the corneal endothelium, IFIOL is a safe procedure. No corneal decompensation was encountered in the current study. But long-term cohort studies are necessary to evaluate endothelial cell loss, especially in those patients undergoing multiple surgeries. 
IFIOLs have been around for nearly four decades with mixed results. Most of the problems and complications with the earlier versions have been solved with improved design, manufacturing techniques, and surgical technique, thanks to the efforts of its inventors Dr. John Worst and Dr. Daljit Singh. $1,6,7,15,16,17,18$

\section{Conclusion}

The long-term results demonstrate that posterior IFIOL implantation is a safe and effective method for correction of aphakia in patients without capsule support. It may be considered an easier and faster option with minimal manipulation to anterior segment structures in paediatric and post-traumatic aphakic eyes.-7,10,13 Further long-term studies are required to evaluate the intraocular position of IFIOL in the growing eyes of children and the endothelial cell loss in different etiological types of aphakia.

\section{Acknowledgements}

We are thankful for the kind help by Dr. Satyajit MV and Dr. Boopathy Murugavel for their clinical input in the course of this study.

\section{References}

1. Gicquel JJ, Langman ME, Dua HS. Iris claw lenses in aphakia. Br J Ophthalmol. 2009;93(10):1273-1275.

2. Sawada T, Kimura W, Kimura T, et al. Long-term follow-up of primary anterior chamber intraocular lens implantation. J Cataract Refract Surg. 1998;24(11):1515-1520.

3. Kwong YY, Yuen HK, Lam RF, Lee VY, Rao SK, Lam DS. Comparison of outcomes of primary scleralfixated versus primary anterior chamber intraocular lens implantation in complicated cataract surgeries. Ophthalmology. 2007;114(1):80-85.

4. Bellucci R, Pucci V, Morselli S, Bonomi L. Secondary implantation of angle-supported anterior chamber and scleral-fixated posterior chamber intraocular lenses. J Cataract Refract Surg. 1996;22(2):247-252.

5. Lett KS, Chaudhuri PR. Visual outcomes following Artisan aphakia iris claw lens implantation. Eye. 2011;25(1):73-76.

6. Koss MJ, Kohnen T. Intraocular architecture of secondary implanted anterior chamber iris-claw lenses in aphakic eyes evaluated with anterior segment optical coherence tomography. $\mathrm{Br} J$ Ophthalmol. 2009;93(10):1301-1306.

7. Baykara M, Ozcetin H, Yilmaz S, Timuçin ÖB. Posterior iris fixation of the iris-claw intraocular lens implantation through a scleral tunnel incision. Am J Ophthalmol. 2007;144(4):586-591.

8. De Silva SR, Arun K, Anandan M, Glover N, Patel CK, Rosen P. Iris-claw intraocular lenses to correct aphakia in the absence of capsule support. J Cataract Refract Surg. 2011;37(9):1667-1672.

9. Gonnermann J, Torun N, Klamann MK, et al. Visual outcomes and complications following posterior iris-claw aphakic intraocular lens implantation combined with penetrating keratoplasty. Graefes Arch Clin Exp Ophthalmol. 2013;251(4):1151-1156.

10. Bhandari V, Reddy JK, Karandikar S, Mishra I. Retro-pupillary iris fixated intraocular lens in pediatric subluxated lens. Journal of Clinical Ophthalmology and Research. 2013;1(3):151.

11. Rao R, Sasidharan A. Iris claw intraocular lens: a viable option in monocular surgical aphakia. Indian J Ophthalmol. 2013;61(2):74. 
12. Gonnermann J, Torun N, Klamann MK, et al. Posterior iris-claw aphakic intraocular lens implantation in children. Am J Ophthalmol. 2013;156(2):382-386.

13. Güell JL, Manero F. Artiflex (foldable iris claw IOL) secondary implantation for correction of aphakia after penetrating ocular injury. J Refract Surg. 2004;20(3):282-283.

14. Odenthal MT, Sminia ML, Liesbeth JJ, Gortzak-Moorstein N, Völker-Dieben HJ. Long-term follow-up of the corneal endothelium after artisan lens implantation for unilateral traumatic and unilateral congenital cataract in children: two case series. Cornea. 2006;25(10):1173-1177.

15. Gicquel JJ, Guigou S, Bejjani RA, Briat B, Ellies P, Dighiero P. Ultrasound biomicroscopy study of the Verisyse aphakic intraocular lens combined with penetrating keratoplasty in pseudophakic bullous keratopathy. J Cataract Refract Surg. 2007;33(3):455-464.

16. Worst JG, Massaro RG, Ludwig HH. The introduction of an artificial lens into the eye using Binkhorst's technique. Ophthalmologica. 1972;164(5):387-391.

17. Mohr A, Hengerer F, Eckardt C. [Retropupillary fixation of the iris claw lens in aphakia. 1 year outcome of a new implantation techniques]. Der Ophthalmologe: Zeitschrift der Deutschen Ophthalmologischen Gesellschaft. 2002;99(7):580-583.

18. Menezo JL, Martinez MC, Cisneros AL. Iris-fixated Worst claw versus sulcus-fixated posterior chamber lenses in the absence of capsular support. J Cataract Refract Surg. 1996;22(10):1476-1484. 